\title{
IMPROVED FISCHER-TROPSCH SLURRY REACTORS
}

\section{TOPICAL REPORT}

Start Date: 2001

End Date: 2009

By

Andrew Lucero

March 2009

Work Performed Under Cooperative Agreement

JSR Task 26 under DE-FC26-98FT40323

For

PowerEnerCat, Inc.

Lakewood, Colorado

And

U. S. Department of Energy

National Energy Technology Laboratory

Morgantown, West Virginia

By

Western Research Institute

Laramie, Wyoming

Kamalendu Das

Task 26 


\section{TABLE OF CONTENTS}

Page

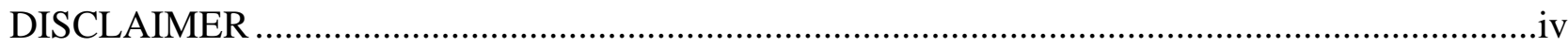

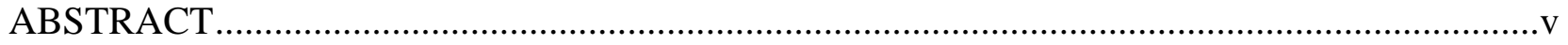

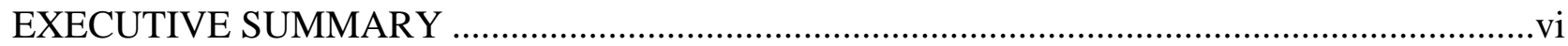

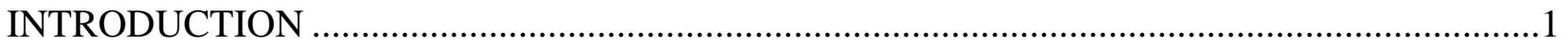

OBJECTIVES

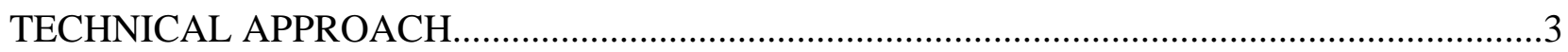

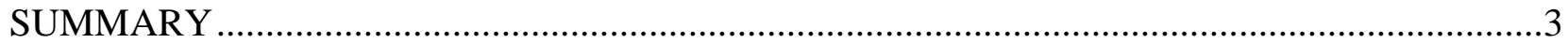

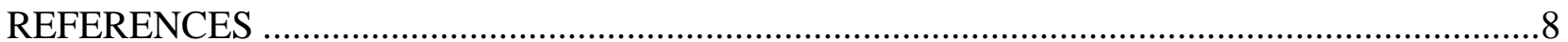




\section{LIST OF FIGURES}

\section{Figures}

2. Bench-scale SCBR Without Steam Jacket......................................................................

3. Porous Metal Sparger Manufactured by Mott Corporation ....................................................5

4. Static Mixer Elements Provided by Koch-Glitch ................................................................6

5. Structured Mass Transfer Packing Manufactured by Montz ...................................................6

6. Structured Packing Manufactured by Montz ....................................................................... 


\section{DISCLAIMER}

This report was prepared as an account of work sponsored by an agency of the United States Government. Neither the United States Government nor any agency thereof, nor any of their employees makes any warranty, express or implied, or assumes any legal liability or responsibility for the accuracy, completeness, or usefulness of any information, apparatus, product, or process disclosed or represents that its use would not infringe on privately owned rights. Reference herein to any specific commercial product, process, or service by trade name, trademark, manufacturer, or otherwise does not necessarily constitute or imply endorsement, recommendation, or favoring by the United States Government or any agency thereof. The views and opinions of authors expressed herein do not necessarily state or reflect those of the United States Government or any agency thereof. 


\begin{abstract}
The conversion of synthesis gas to hydrocarbons or alcohols involves highly exothermic reactions. Temperature control is a critical issue in these reactors for a number of reasons. Runaway reactions can be a serious safety issue, even raising the possibility of an explosion. Catalyst deactivation rates tend to increase with temperature, particularly of there are hot spots in the reactor. For alcohol synthesis, temperature control is essential because it has a large effect on the selectivity of the catalysts toward desired products. For example, for molybdenum disulfide catalysts unwanted side products such as methane, ethane, and propane are produced in much greater quantities if the temperature increases outside an ideal range.

Slurry reactors are widely regarded as an efficient design for these reactions. In a slurry reactor a solid catalyst is suspended in an inert hydrocarbon liquid, synthesis gas is sparged into the bottom of the reactor, un-reacted synthesis gas and light boiling range products are removed as a gas stream, and heavy boiling range products are removed as a liquid stream. This configuration has several positive effects for synthesis gas reactions including: essentially isothermal operation, small catalyst particles to reduce heat and mass transfer effects, capability to remove heat rapidly through liquid vaporization, and improved flexibility on catalyst design through physical mixtures in addition to use of compositions that cannot be pelletized. Disadvantages include additional mass transfer resistance, potential for significant back-mixing on both the liquid and gas phases, and bubble coalescence.
\end{abstract}

In 2001 a multiyear project was proposed to develop improved FT slurry reactors. The planned focus of the work was to improve the reactors by improving mass transfer while considering heat transfer issues. During the first year of the project the work was started and several concepts were developed to prepare for bench-scale testing. PowerEnerCat was unable to raise their cash contribution for the project, and the work was stopped. This report summarizes some of the progress of the project and the concepts that were intended for experimental tests. 


\section{EXECUTIVE SUMMARY}

The conversion of synthesis gas to hydrocarbons or alcohols involves highly exothermic reactions. Temperature control is a critical issue in these reactors for a number of reasons. Runaway reactions can be a serious safety issue, even raising the possibility of an explosion. Catalyst deactivation rates tend to increase with temperature, particularly of there are hot spots in the reactor. For alcohol synthesis, temperature control is essential because it has a large effect on the selectivity of the catalysts toward desired products. For example, for molybdenum disulfide catalysts unwanted side products such as methane, ethane, and propane are produced in much greater quantities if the temperature increases outside an ideal range.

Slurry reactors are widely regarded as an efficient design for these reactions. In a slurry reactor a solid catalyst is suspended in an inert hydrocarbon liquid, synthesis gas is sparged into the bottom of the reactor, un-reacted synthesis gas and light boiling range products are removed as a gas stream, and heavy boiling range products are removed as a liquid stream. This configuration has several positive effects for synthesis gas reactions including: essentially isothermal operation, small catalyst particles to reduce heat and mass transfer effects, capability to remove heat rapidly through liquid vaporization, and improved flexibility on catalyst design through physical mixtures in addition to use of compositions that cannot be pelletized. Disadvantages include additional mass transfer resistance, potential for significant back-mixing on both the liquid and gas phases, and bubble coalescence.

In 2001 a multiyear project was proposed to develop improved FT slurry reactors. The planned focus of the work was to improve the reactors by improving mass transfer while considering heat transfer issues. During the first year of the project the work was started and several concepts were developed to prepare for bench-scale testing. PowerEnerCat was unable to raise their cash contribution for the project, and the work was stopped. This report summarizes some of the progress of the project and the concepts that were intended for experimental tests. 


\section{INTRODUCTION}

In the past several years, a number of economic and political issues have brought increased focus and interest in Fischer-Tropsch (FT) processes to produces fuels and chemicals from carbonaceous feedstocks such as natural gas, biomass, and coal. Some of these issues include dramatic increases in oil prices observed in recent years and the fact that a large fraction of oil is supplied by countries unfriendly to the United States. Although oil is now trading at less than one third the maximum prices observed last year due to the global recession, the prices are expected to spike again when the global economies recover. The price hikes combined with the fact that the U.S. imports two thirds of its oil both have spurred development of processes for production of alternative fuels. While a huge fraction of recent investments have focused on production of ethanol as a fuel additive, FT processes for gas-to-liquid (GTL), biomass-to-liquids (BTL), and coal-to-liquids (CTL) have all increased as well.

FT Synthesis is a method of thermochemically producing fuels and chemicals from carbonaceous feedstocks. There are two main processing steps in FT synthesis. The first step involves converting carbonaceous feedstock to synthesis gas in a gasifier (solid feedstocks) or a partial oxidation unit or reformer (gaseous feedstocks). The second step is to convert synthesis gas to products in a pressurized catalytic reactor. Thermal management is a critical issue for the reactor that converts synthesis gas to fuels because FT reactions are highly exothermic and catalyst life and selectivity toward desired products (compared to unwanted byproducts) normally depends on maintaining the operating temperature in a narrow range. Currently reactors must be constructed at large scale to produce fuels at a reasonable price.

Slurry reactors have many advantages over multitubular fixed bed reactors for FT applications including simpler construction, lower capital cost, excellent temperature control, lower pressure drops, and capability for online addition and removal of catalyst. Key disadvantages include additional mass transfer resistance (synthesis gas must transfer through the slurry liquid to contact the catalyst), and extremely complex multiphase behaviors under industrial conditions. The importance of the issue is reflected in the amount of research published on the subject even in the past ten years. R. Krishna's research group ${ }^{1-7}$ has been studying slurry bubble columns (SCBR) for nearly 20 years. Many of the papers specifically explore mass transfer or scale up issues. Gamwo et al. ${ }^{8}$ developed a mathematical model to examine the hydrodynamics of slurry bubble column reactors. They then utilized the model to determine optimum catalyst size, an issue typically not addressed in the literature. Meikap et al. ${ }^{9}$ conducted experiments to evaluate the interfacial area in a multistage bubble column. However, the column was conceived as a wet scrubber for air pollution control, and it is unclear how the results would translate to a high pressure reactor. Inga and Morsi ${ }^{10}$ examined the 
effects of gas velocity, system pressure, and catalyst loading on the gas holdup in an SCBR operating with a commercial iron FT catalyst. Their results showed that gas holdup increased with pressure due to small bubbles and increased with superficial gas velocity due to large bubbles. They also found that increased catalyst loading decreased holdup by decreasing small bubbles. Thorat et al. ${ }^{11}$ studied the effect of sparger design on bubble columns using perforated plates. They note that the sparger design is most important for columns with a height to diameter ratio less than 5 . The model they developed correlated their data within $\pm 10 \%$. Rados et al. ${ }^{12-13}$ developed and tested a multicomponent, one dimensional, compartment-based dynamic model to evaluate slurry bubble column reactors with systems consisting of both contraction and expansion in the gas phase during reaction. An axial dispersion component of the model accounts for backmixing of small bubbles, large bubbles, and slurry. They also performed a detailed analysis of the role of backmixing on the performance of FT synthesis (contraction of gas phase). More recently Iliuta ${ }^{14}$ et al. used simulations to compare cobalt and iron based FT synthesis slurry bubble column reactors. For both catalysts they determined that the superficial gas velocity directly affected the gas residence time, in turn affecting temperature and conversions. Wang et al. ${ }^{15}$ presented a comprehensive examination of literature pertaining to slurry reactors for gas to liquid processes. Their review of over 200 articles, most published in the last 20 years, still recommends more studies for development and design of high performance slurry reactors.

\section{OBJECTIVES}

The overall objective for the project was to develop improved slurry reactor designs for converting synthesis gas to liquid fuel products, particularly alcohols. Specific objectives were:

- Prepare a baseline set of data using a bench-scale slurry bubble column reactor

- Design and construct improved reactors, particularly to improve mass transfer

- Test the improved reactors using an alcohol synthesis catalyst (molybdenum disulfide based)

- Confirm the improved design with an alternative alcohol synthesis catalyst including:

o Prepare a baseline set of data for the alternate catalyst

o Test the optimal new design

- As time and funding permit, test the design for Fischer-Tropsch hydrocarbon synthesis 


\section{TECHNICAL APPROACH}

The general approach to this project was to identify and/or design and fabricate equipment that will improve gas-liquid contact, mass transfer area, and heat transfer characteristics in slurry reactors. Several Approaches were considered to accomplish the goals. Interfacial area for mass transfer is proportional to the size of the gas bubbles. Several methods were considered to generate smaller bubbles. Column internals such as mass transfer packings and inline static mixers were considered to maintain distribution of gas bubbles in the slurry phase. In reactors where the slurry is circulated, mixers could also help heat transfer by distributing the liquid across the diameter of the column.

To begin initial development, two small slurry bubble column reactors were fabricated (Figures 1 and 2). The intent of these reactors was to test the effect of various methods of generating small bubbles and test the effect of some internals on the performance for mixed alcohol synthesis. Specific concepts for generating small or microbubbles included sonication and porous metal frits. Working with a sonicator manufacturer, a conceptual design was developed to use a sonicator to generate microbubbles which would then enter the reaction zone of the SCBR. A key difficulty was reducing the temperature near the sonicator to an acceptable range. Porous metal frits or spargers such as the one pictured in Figure 3 (Mott Corporation) are much easier to implement. They typically have a narrow operating range, and sometimes can have large pressure drops if not sized properly. It is not clear what if any effect catalyst particles might have on the sparger.

Several items were considered as internals for the SCBRs including: glass balls, ceramic saddles, static mixer elements, and structured mass transfer column packings. Figure 4 shows static mixer elements provided by Koch-Glitsch for testing. They are now manufactured by Sulzer Chemtech. Figures 5 and 6 show an element of structured mass transfer packing manufactured by Montz. Both Koch-Glitsch and Sulzer Chemtech market competing structured packings for mass transfer applications. They are not typically used for applications where the column is totally flooded. Although the packings provide excellent distribution of gas and liquid across the column in addition to excellent gas-liquid contact, it is unclear if the channels would eventually plug with catalyst. Both Koch-Glitsch and Sulzer Chemtech market versions of the structured packing in which catalyst is enclosed in fixed wire gauze wraps inside the packing. Professor Krishna's research group is currently testing this concept in an SCBR arrangement. The disadvantage to all the structured internals is that there is no heat transfer capability in the packed sections. This issue would require alternating packed sections of an SCBR with heat transfer sections. Sulzer Chemtech markets an SMR mixer reactor which combines mixing and heat exchange capability, but it is unclear how large the reactor can be scaled. The complexity may make the cost prohibitive compared 
to simpler SCBR designs, and to date, performance advantages have not been demonstrated for FT synthesis.

\section{SUMMARY}

Slurry bubble column reactors are now widely considered as the best choice for large scale Fischer-Tropsch synthesis. Although SCBRs are being successfully used as commercial scale for methanol synthesis and FT synthesis, there are still many opportunities to improve the designs. Column internals could be a promising method to improved mass transfer and hydrodynamics, particularly in cases where high gas velocities are used.

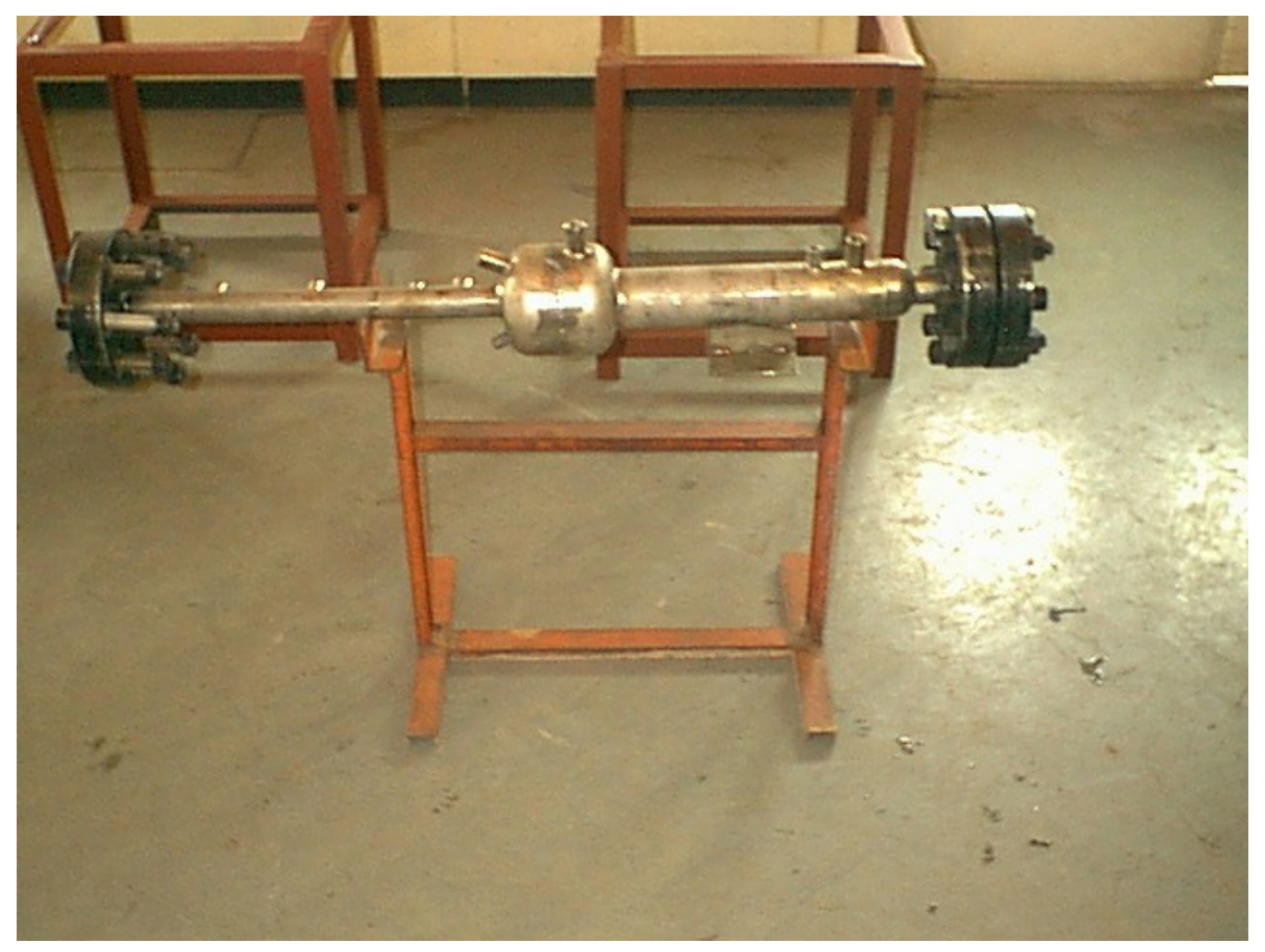

Figure 1. Bench-scale SCBR with Steam Jacket 


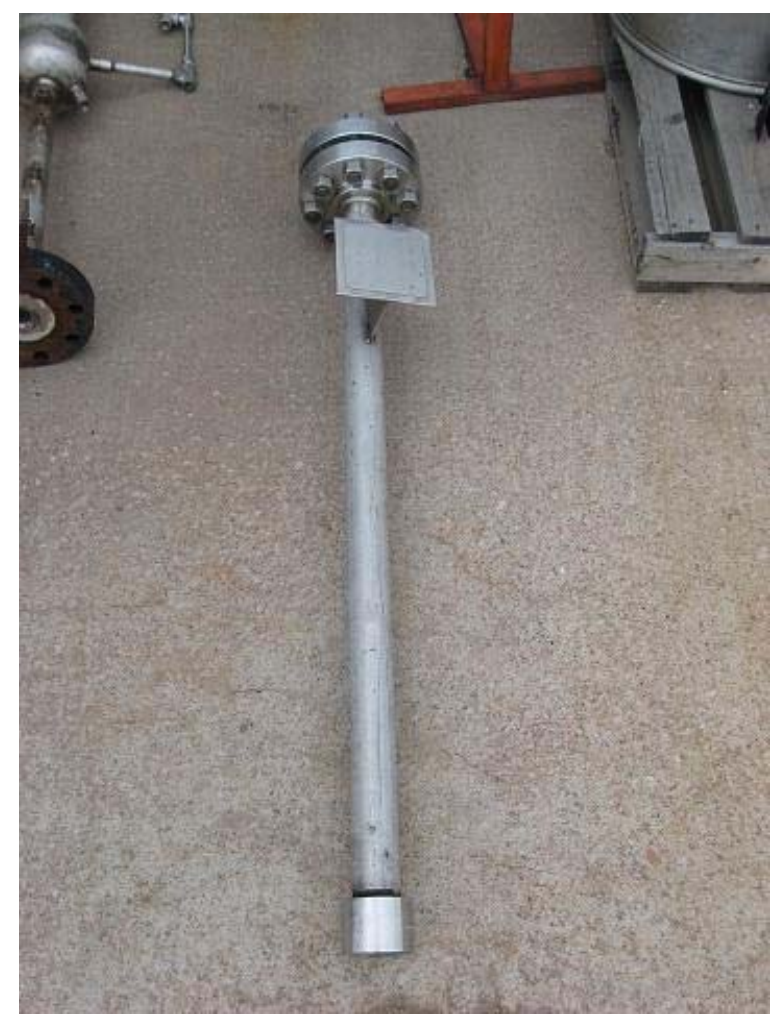

Figure 2. Bench-Scale SCBR without Steam Jacket

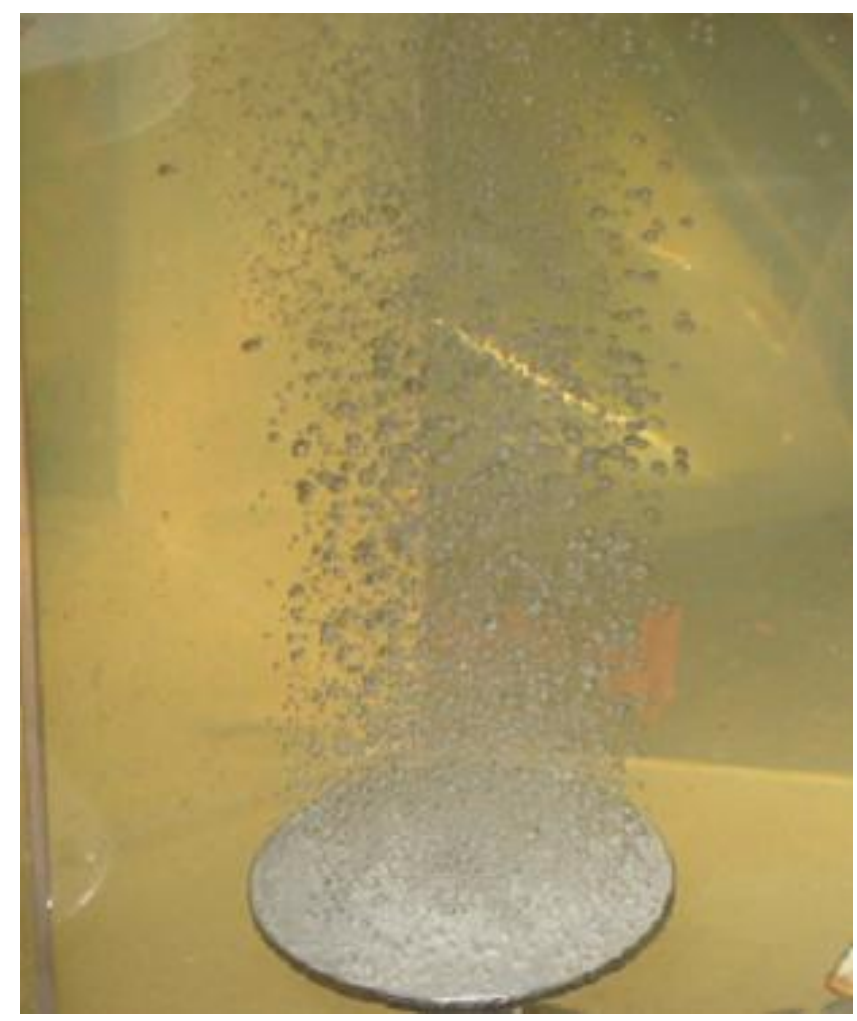

Figure 3. Porous Metal Sparger manufactured by Mott Corp. 


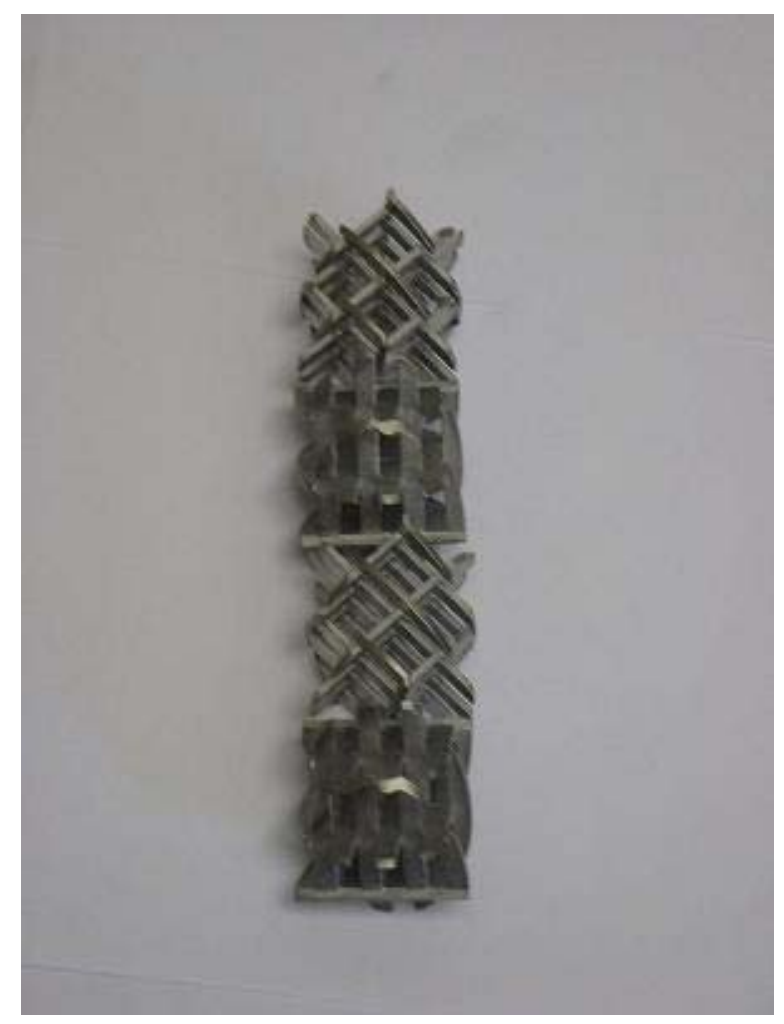

Figure 4. Static Mixer Elements Provided by Koch-Glitsch

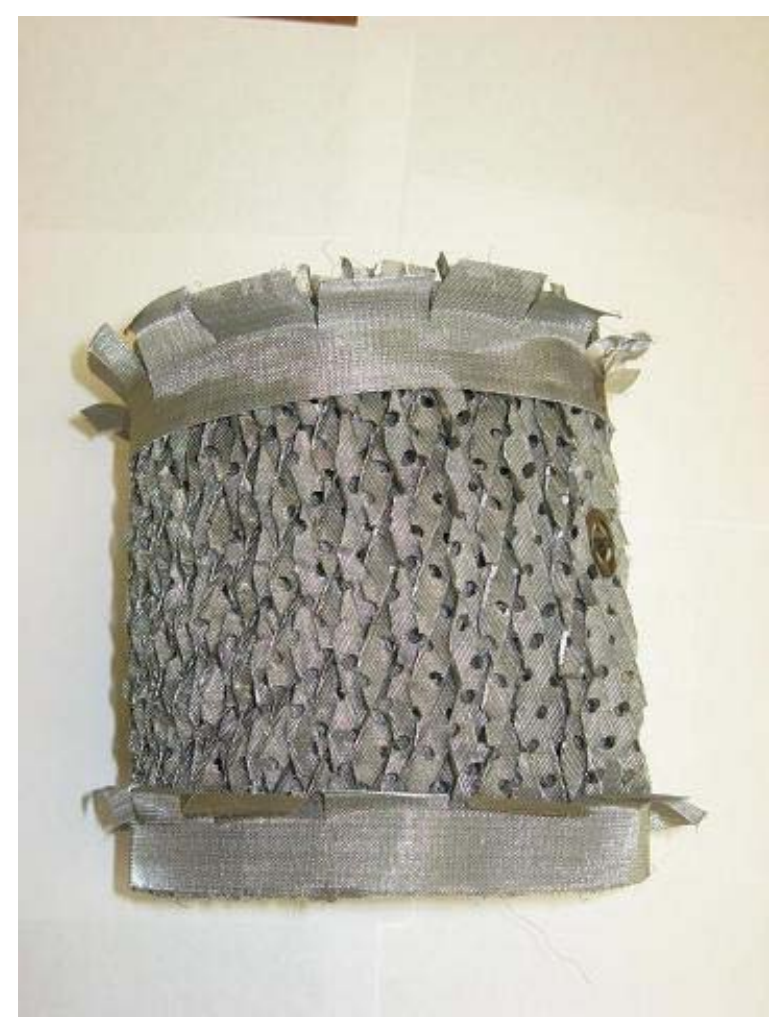

Figure 5. Structured Mass Transfer Packing Manufactured by Montz 


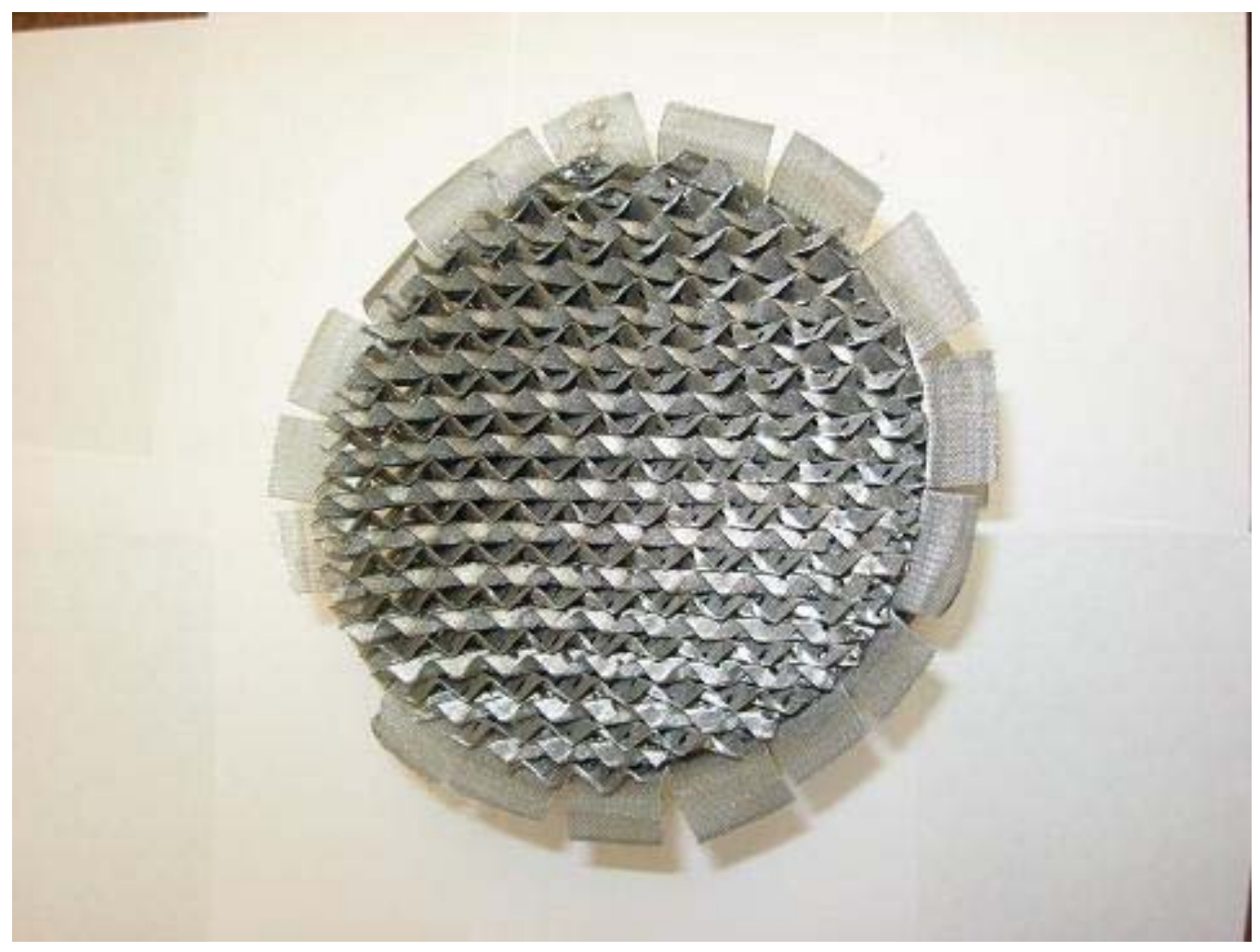

Figure 6. Structured Packing Manufactured by Montz.

\section{REFERENCES}

${ }^{1}$ Krishna, R. Urseanu, M.I., van Baten, J.M., Ellenberger, J, "Rise velocity of a swarm of large gas bubbles in liquid." Department of Chemical Engineering, University of Amsterdam, 54, 171-183 (1999).

${ }^{2}$ Krishna, R., van Baten, J.M., Urseanu, M.I., “Three-phase Eulerian simulations of bubble column reactors operating in the churn-turbulent regime: a scale up strategy" Department of Chemical Engineering, University of Amsterdam, 55, 3275-3286 (2000).

${ }^{3}$ Krishna, R., van Baten, J.M., Urseanu, M.I.,Ellenberger, J. “A scale up strategy for bubble column slurry reactors", Department of Chemical Engineering, University of Amsterdam, 66, 199-207 (2001)

${ }^{4}$ Forret, A., Schweitzer, J-M., Gauthier, T., Krishna, R. and Schweich, D., "Scale up of slurry bubble reactors,” Oil \& Gas Science and Technology, Revue de L'Institut Francais du Petrole, 61, 443 - 458 (2006)

${ }^{5}$ Vandu, C.O., van den Berg, B., and Krishna, R., "Gas-Liquid Mass Transfer in a Slurry Bubble Column at High Slurry Concentrations and High Gas Velocities," Chemical Engineering \& Technology, 28, 998-1002 (2005) 
${ }^{6}$ Vandu, C.O. and Krishna, R., "Influence of scale on the volumetric mass transfer coefficients in bubble columns,” Chemical Engineering \& Processing 43, 575-579 (2004)

${ }^{7}$ Vandu, C.O. and Krishna, R., "Volumetric mass transfer coefficients in slurry bubble columns operating in the churn-turbulent flow regime," Chemical Engineering \& Processing, 43, 987 - 995 (2004)

${ }^{8}$ Gamwo, I. K., Gidaspow, D., Jung, J., “Optimum catalyst size for slurry bubble column reactors", Department of Chemical and Environmental Engineering, Illinois Institute of Technology, 44, 6393-6402 (2005)

${ }^{9}$ Meikap, B.C., Kundu, G., Biswas, M.N., "Prediction of the Interfacial area of contact in a variable-area multistage bubble column", Department of Chemical Engineering Indian Institute of Technology, Kharagpur India, 40, 6194-6200 (2001)

${ }^{10}$ Inga, J.R., Morsi, B. I., "Effect of Operating variables on the gas holdup in a large-scale slurry bubble column reactor operating with an organic liquid mixture" Chemical and Petroleum Engineering Department, University of Pittsburgh, 38, 928-937 (1999)

${ }^{11}$ Thorat, B. N., Katarie, K., Kulkarni, A.V., Joshi, J. B., "Pressure drop studies in bubble columns”, Department of Chemical Technology, University of Mumbai, India, 40, 36753688 ( 2001)

${ }^{12}$ Rados, N., Al-Dahhan, M.H., Dudukovic, M.P., "Dynamic Modeling of slurry bubble column reactors”, Catalyst Today, 79-80, 211-218, (2003)

${ }^{13}$ Rados, N., Al-Dahhan, M.H., Dudukovic, M.P., "Dynamic Modeling of slurry bubble column reactors”, Chemical Reaction Engineering Laboratory, Washington University, St. Louis, 44, 6086-6094 (2005)

${ }^{14}$ Iluita, I., Larachi, F.,Anfray, J., Dromard, N., Schweich, D., "Comparative simulations of cobalt-and iron-based fischer-tropsch synthesis slurry bubble column reactors" Department of Chemical Engineering, Laval University, Quebec Canada, 47, 3861-3869, (2008)

${ }^{15}$ Wang, T., Wang, J., Jin, Y., "Slurry reactors for gas-to-liquid processes: A review, Beijing Key Laboratory of Green Reaction Engineering and Technology, Department of Chemical Engineering, Tsinghua University, Beijing China, 46, 5824-5847 (2007) 